\title{
Validity of the Barrow Neurological Institute (BNI) screen for higher cerebral functions in stroke patients with good functional outcome
}

Citation for published version (APA):

Boosman, H., Visser-Meily, J. M. A., Post, M. W. M., Duits, A., \& van Heugten, C. M. (2013). Validity of the Barrow Neurological Institute (BNI) screen for higher cerebral functions in stroke patients with good functional outcome. Neuropsychology, Development and Cognition. Section D: The Clinical Neuropsychologist, 27(4), 667-680. https://doi.org/10.1080/13854046.2013.777787

Document status and date:

Published: 01/01/2013

DOI:

10.1080/13854046.2013.777787

Document Version:

Publisher's PDF, also known as Version of record

Document license:

Taverne

Please check the document version of this publication:

- A submitted manuscript is the version of the article upon submission and before peer-review. There can be important differences between the submitted version and the official published version of record.

People interested in the research are advised to contact the author for the final version of the publication, or visit the DOI to the publisher's website.

- The final author version and the galley proof are versions of the publication after peer review.

- The final published version features the final layout of the paper including the volume, issue and page numbers.

Link to publication

\footnotetext{
General rights rights.

- You may freely distribute the URL identifying the publication in the public portal. please follow below link for the End User Agreement:

www.umlib.nl/taverne-license

Take down policy

If you believe that this document breaches copyright please contact us at:

repository@maastrichtuniversity.nl

providing details and we will investigate your claim.
}

Copyright and moral rights for the publications made accessible in the public portal are retained by the authors and/or other copyright owners and it is a condition of accessing publications that users recognise and abide by the legal requirements associated with these

- Users may download and print one copy of any publication from the public portal for the purpose of private study or research.

- You may not further distribute the material or use it for any profit-making activity or commercial gain

If the publication is distributed under the terms of Article $25 \mathrm{fa}$ of the Dutch Copyright Act, indicated by the "Taverne" license above, 


\section{The Clinical Neuropsychologist}

\section{Validity of the Barrow Neurological Institute (BNI) Screen for Higher Cerebral Functions in Stroke Patients with Good Functional Outcome}

Hileen Boosman , Johanna M. A. Visser-Meily, Marcel W. M. Post , Annelien Duits \& Caroline M. van Heugten

To cite this article: Hileen Boosman , Johanna M. A. Visser-Meily , Marcel W. M. Post , Annelien Duits \& Caroline M. van Heugten (2013) Validity of the Barrow Neurological Institute (BNI) Screen for Higher Cerebral Functions in Stroke Patients with Good Functional Outcome, The Clinical Neuropsychologist, 27:4, 667-680, DOI: 10.1080/13854046.2013.777787

To link to this article: https://doi.org/10.1080/13854046.2013.777787

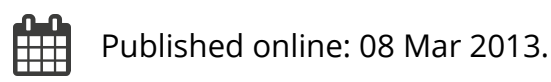

Submit your article to this journal ๘

Lll Article views: 379

Q View related articles ¿

Citing articles: 3 View citing articles $[3$ 


\title{
Validity of the Barrow Neurological Institute (BNI) Screen for Higher Cerebral Functions in Stroke Patients with Good Functional Outcome
}

\author{
Hileen Boosman ${ }^{1}$, Johanna M. A. Visser-Meily ${ }^{1}$, Marcel W. M. \\ Post $^{1}$, Annelien Duits ${ }^{2}$, and Caroline M. van Heugten ${ }^{2,3}$ \\ ${ }^{1}$ Rudolf Magnus Institute of Neuroscience and Center of Excellence for Rehabilitation \\ Medicine, University Medical Center Utrecht and De Hoogstraat Rehabilitation, Utrecht, The \\ Netherlands \\ ${ }^{2}$ Maastricht University Medical Center (MUMC), Department of Psychiatry and Psychology, \\ School for Mental Health and Neuroscience, Maastricht, The Netherlands \\ ${ }^{3}$ Maastricht University, Department of Neuropsychology and Psychopharmacology, Maastricht, \\ The Netherlands
}

Cognitive impairments are often under diagnosed in stroke patients with good functional outcome. There is a need for a cognitive screening instrument that is sufficiently sensitive to cognitive impairments in these stroke patients. For this goal, we tested the feasibility and validity of the Barrow Neurological Institute Screen for Higher Cerebral Functions (BNIS). Stroke patients with good functional outcome (Barthel Index 19/20) within 1 year poststroke were administered the BNIS and a brief neuropsychological assessment (NPA) including tests for perception, language, memory, attention, reasoning, and executive functioning. We compared the BNIS with the NPA to investigate its feasibility, internal consistency, floor and ceiling effects, concurrent validity, sensitivity and specificity. Fifty-four stroke patients were included. It took significantly less time to administer the BNIS (median $=16$ minutes) than the NPA (median $=32.7$ minutes). The BNIS showed good internal consistency $($ alpha $=.82$ ) and no floor or ceiling effects. The recommended cutoff values yielded good sensitivity and low to good specificity, depending on age. Except for perception (Spearman correlation .33), BNIS domain scores were significantly $(0.44-0.55)$ associated with matching neuropsychological tests. This study provides promising results for the BNIS as a measure to detect cognitive impairments in stroke patients with good functional outcome.

Keywords: Stroke; Cognition disorders; Neuropsychological tests; Validity.

\section{INTRODUCTION}

Stroke patients with good functional outcome-those who show no immediate significant motor, sensory, or linguistic symptoms - are often discharged home within days and are usually not referred to a rehabilitation program (Planton et al., 2012). Although there might be moments of poststroke monitoring, these patients are presumed to continue their social, family, and professional life as it was before their

Special thanks to Jasmijn Kromhout, Anneke Nieuwenhuis and Jeanette Drost for their assistance in data collection.

Address correspondence to: C. M. van Heugten, Maastricht University, School for Mental Health and Neuroscience, Department of Psychiatry and Neuropsychology, P.O. Box 616, 6200 MD Maastricht, The Netherlands. E-mail: c.vanheugten@maastrichtuniversity.nl Accepted for publication: February 14, 2013. First published online: March 7, 2013 
stroke (Planton et al., 2012). Although it was long thought that these patients have no cognitive impairments, recent studies have suggested otherwise (Carlsson, Möller, \& Blomstrand, 2003; Planton et al., 2012; Schweizer, Al-Khindi, \& Macdonald, 2012).

A recent study reported that ischemic stroke patients with good recovery (i.e., no sensorymotor, language, or neglect deficit) showed impairments in executive functioning, attention, and memory (Planton et al., 2012). Another study reported that $42 \%$ of aneurysmal subarachnoid hemorrhage $(\mathrm{aSAH})$ patients, who had good outcome on the Glasgow Outcome Scale, showed cognitive impairments over 2 years after aSAH (Schweizer et al., 2012). These studies indicate the need of standard assessment of cognitive functioning even in stroke patients with good functional outcome to trace cognitive impairments timely. Comprehensive neuropsychological assessment (NPA) is the most sensitive method to assess cognitive functioning but can take hours to complete (Hachinski et al., 2006). Screening procedures would be helpful to assess all stroke patients, but these need to be sufficiently sensitive to trace the often subtle impairments in, for example, memory, executive functioning, or reasoning.

A well known screening instrument is the Mini-Mental State Examination (MMSE; Folstein, Folstein, \& McHugh, 1975). The MMSE was developed for patients with dementia, but is commonly used to screen for cognitive impairments in patients with stroke. However, the MMSE has a predominance of language and memory items (Aggarwal \& Kean, 2010) and appears insensitive to right hemisphere lesions (Dick et al., 1994; Grace et al., 1995), minor cognitive impairments (Toglia, Fitzgerald, O’Dell, Mastrogiovanni, \& Lin, 2011; Schweizer et al., 2012), and subcortical cognitive functions (de Koning, van Kooten, \& Koudstaal, 1998). The MMSE also proved to be insensitive to impairments in abstract reasoning, executive functions, and visual perception and construction (Nys et al., 2005a).

A more recently developed cognitive screening instrument that was developed to overcome the shortcomings of the MMSE, is the Montreal Cognitive Assessment (MoCA; Nasreddine et al., 2005). A previous study reported that more than half of patients with stroke or transient ischemic attack with an adequate MMSE score showed impaired performance on the MoCA (Pendlebury, Cuthbertson, Welch, Mehta, \& Rothwell, 2010). Recent studies have, however, also indicated that the $\mathrm{MoCA}$ is not superior to the MMSE regarding the prediction of a 3-month functional outcome after aSAH (Wong et al., 2012), and that the MoCA is relatively insensitive to nonmemory domain impairments (Pendlebury, Mariz, Bull, Mehta, \& Rothwell, 2012). Furthermore, the MoCA includes only few items for each cognitive domain and may therefore not fully capture the subtle cognitive consequences of stroke patients with good functional outcome. We therefore considered the Barrow Neurological Institute Screen for Higher Cerebral Functions (BNIS; Prigatano, 1991; Prigatano, Amin, \& Rosenstein, 1995), a more comprehensive cognitive screening instrument. The BNIS was originally developed for patients with brain injury. The BNIS is unique in its measurement of the patient's awareness of basic memory functions, and evaluation of affect expression and perception. Compared to the MoCA, the BNIS covers more items within each cognitive domain which increases the chance of finding a cognitive impairment when present. For example, within the perception domain the BNIS quickly assesses a multitude of items (object and pattern recognition, constructional praxis, scanning, sequencing, copying), whereas the MoCA only includes clock drawing and cube copying. 
Previous studies have reported good psychometric properties for the BNIS in patients with brain injury. The BNIS has adequate sensitivity (83-96\%) and specificity (46-87\%) for detecting cognitive impairments (Denvall, Elmståhl, \& Prigatano, 2002; Hofgren, Esbjörnsson, Aniansson, \& Sunnerhagen, 2007; Prigatano, 1991; Prigatano, Amin, \& Rosenstein, 1992, Prigatano et al., 1995). In addition, previous studies reported significant associations between the BNIS and various neuropsychological measures, supporting its concurrent validity (Prigatano \& Palencia, 2000; Prigatano, 2004; see also Lai \& Prigatano, 2004). A next step would be to examine the use of the BNIS in stroke patients with good functional outcome. Therefore, the objective of the current study was to assess the feasibility and validity of the BNIS in stroke patients with good functional outcome.

\section{METHOD}

\section{Participants and procedure}

Data were used from patients who visited the outpatient clinics of the University Medical Center Utrecht (UMCU) and the Maastricht University Medical Center

Table 1. Characteristics of the stroke sample

\begin{tabular}{|c|c|}
\hline Gender, female & $35.2 \%$ \\
\hline Mean age in years $(S D)^{\mathrm{a}}$ & $53.8(12.3)$ \\
\hline Age range & $19-77$ \\
\hline High education $^{\mathrm{b}}$ & $33.3 \%$ \\
\hline Living with partner & $83.3 \%$ \\
\hline \multicolumn{2}{|l|}{ Current employment status } \\
\hline Student & $1.9 \%$ \\
\hline Fulltime/Parttime & $33.4 \%$ \\
\hline Housemaker & $3.7 \%$ \\
\hline Sick leave & $33.4 \%$ \\
\hline Retired & $24.1 \%$ \\
\hline Unknown & $3.7 \%$ \\
\hline \multicolumn{2}{|l|}{ Handedness } \\
\hline Left & $11.1 \%$ \\
\hline Right & $88.9 \%$ \\
\hline \multicolumn{2}{|l|}{ Type of stroke and location } \\
\hline Ischemic & $46.3 \%$ \\
\hline Left hemisphere & $44.0 \%$ \\
\hline Right hemisphere & $44.0 \%$ \\
\hline Left and right hemisphere & $8.0 \%$ \\
\hline Unknown location & $4.0 \%$ \\
\hline Hemorrhagic & $11.1 \%$ \\
\hline Left hemisphere & $50.0 \%$ \\
\hline Right hemisphere & $33.3 \%$ \\
\hline Left and right hemisphere & $16.7 \%$ \\
\hline Subarachnoid hemorrhage & $42.6 \%$ \\
\hline Anterior circulation aneurysm & $47.8 \%$ \\
\hline Posterior circulation aneurysm & $30.4 \%$ \\
\hline Nonaneurysmal & $21.7 \%$ \\
\hline Mean time poststroke in weeks $(S D)^{\mathrm{a}, \mathrm{c}}$ & $15.0(12.8)$ \\
\hline
\end{tabular}

${ }^{\mathrm{a}} S D=$ standard deviation.

${ }^{\mathrm{b}}$ High education $\geqslant$ finished high school; Low education $<$ finished high school.

${ }^{\mathrm{c}} N=52$. 
(MUMC), or the inpatient clinic of De Hoogstraat Rehabilitation, Utrecht, The Netherlands, between August 2009 and May 2011. Stroke patients were included who had suffered from stroke recently ( $<12$ months), who had sufficient command of the Dutch language, and who had good functional outcome in terms of a Barthel Index (Wade \& Collin, 1988) score $\geqslant 19$ points.

A total of 54 patients were included in this study. Of this group, $46.3 \%(n=25)$ of patients had an ischemic stroke, $11.1 \%(n=6)$ a hemorrhagic stroke, and $42.6 \%$ $(n=23)$ a subarachnoid hemorrhage. The mean time between diagnosis and assessment was 15.0 weeks $(S D=12.8)$. Table 1 presents the sample characteristics. All patients completed the BNIS and the brief NPA in the same session with half of all patients starting with the NPA and the other half starting with the BNIS. The time needed to administer the NPA and the BNIS was recorded. The study was conducted according to the Code of Conduct for Medical Research of the Council of the Dutch Federation of Medical Scientific Societies. At these clinics, all patients are informed that their files can be used anonymously for research purposes, unless they object. A review procedure by a medical ethics committee is not needed for use of anonymous routinely collected data.

\section{Materials}

Barthel Index. The Barthel Index contains 10 items about basic self-care and mobility (e.g., washing, transfers). Its total score has a 0-20 range (Wade \& Collin 1988). In accordance with other studies, we used $\geqslant 19$ points as a cutoff value for physical independence (Hankey \& Langhorne, 2006; Schiemanck, Kwakkel, Post, Kappelle, \& Prevo, 2006).

\section{Barrow Neurological Institute Screen for Higher Cerebral Functions}

(BNIS). The BNIS (Prigatano et al., 1995) includes a prescreening of arousal-alertness, basic language abilities, and cooperation on a 3-point rating scale. The prescreening is based on observations by the experimenter. For each item a score of at least 2 is required to administer the BNIS. These three prescreening items contribute to the BNIS total score. The BNIS further contains 27 items in seven domains: language, orientation, attention and concentration, visuospatial problem solving, memory, awareness, and affect. The affect control item is rated by the experimenter based on observations made during assessment. The awareness versus performance item is based on evaluation by the patient. The remaining items are based on actual performance by the patient (e.g., digit span forward and backward, and digit symbol test). Items are summed to obtain domain scores and a total BNIS score. The total BNIS score has a 0-50 range. The total BNIS score has a $0-50$ range. Higher scores indicate better functioning. Interpretation of impaired cognitive performance is based on a cutoff value of $<47$ for patients $\leq 55$ years and $<43$ for patients $>55$ years (Prigatano et al., 1995).

The BNIS has been translated and validated into several languages, among which Swedish (Denvall et al., 2004), German (Momtazi, 2004), Cantonese (Lai \& Prigatano, 2004), and French (Truelle, Marinescu, \& Rusina, 2004). The BNIS was translated into Dutch using a forward-backward translation procedure to ensure equivalence to the original English BNIS. The linguistic properties of the translated 
items were reviewed by three clinical neuropsychologists of whom two are also involved in the present study (C. v. H. and A. D.) and are all specialized in cognitive functioning after acquired brain injury. Five items in the language or the memory domain were adapted to retain the linguistic properties of these items. For example, for the spelling item, instead of the word "diamond" we used a Dutch word "doperwten" in which the "w" is not pronounced, just like the "a" is not pronounced in "diamond". Retaining the intended measurement properties was considered most important. Other properties (e.g., comparison of difficulty to spell "diamond" and "doperwten") were not taken into account.

Neuropsychological assessment (NPA). A brief NPA was used as a gold standard. The brief NPA consisted of a core battery that was administered to all patients. Since the cognitive screening was part of standard care additional neuropsychological tests varied depending on, for instance, cognitive complaints reported by the patient. The core battery consisted of six conventional neuropsychological tests covering six major cognitive domains: perception, language, memory, attention, reasoning, and executive functioning. For the perception domain, the Star Cancellation Test (SCT; Wilson, Cockburn, \& Halligan, 1987) was used. The SCT screens for unilateral spatial neglect. The patient is presented with a sheet of paper that contains small stars, large stars, letters, and short words. The patient is required to cancel out all the small stars. The total number of cancelled stars was noted (score range $0-54$ ). A cutoff value of $<51$ was used to indicate possible unilateral spatial neglect. Language performance was assessed with the Boston Naming Test (BNT; Kaplan, Goodglass, \& Weintraub, 1978) short form. The BNT short form measures object naming from 15 line drawings. The Rey Auditory Verbal Learning Test (RAVLT; Rey, 1958) was used to assess the memory domain. The RAVLT is a verbal memory task that determines immediate recall on five consecutive learning trials (range 0 75), delayed recall (range 0-15), and delayed recognition (range 0-30). For this study, we used only one test score for each cognitive domain and therefore we only included the test score for immediate recall. We chose immediate recall because the majority of BNIS memory items (4 out of 7) focus on immediate recall. For the attention domain the Trail Making Test Part A (TMT-A; Reitan, 1956) was used. The TMT-A is a reaction time measure of psychomotor speed. The patient is required to connect numbers in consecutive order (1, 2, 3, etc.). Abstract reasoning was determined with Raven's Advanced Progressive Matrices (RAPM; Raven, 1994) (short form). The patient is presented with 12 different patterns, each with a missing component. The patient is asked to select the missing component from eight alternatives. The RAPM was added to the NPA because impaired abstract reasoning early after stroke is a predictor of long-term cognitive impairment (Nys et al., 2005b). For the executive domain, the Stroop Color and Word Test (Stroop, 1935) was used. The Stroop is a measure of speed of information processing and response inhibition. The Stroop test consists of three parts: (1) reading color words printed in black ink; (2) naming colors; and (3) reading color words printed in incongruent colors. For the current study the variable of interest was the Stroop interference score. The neuropsychological tests are described in more detail elsewhere (Lezak, Howieson, \& Loring, 2004). Dutch norms were used when available. Scores below the 5th percentile or within the first decile were considered impaired. Performance on the total 
NPA was considered impaired when there was impaired performance on at least one neuropsychological test.

\section{Statistical analysis}

Nonparametric statistics (Mann-Whitney U-test, Spearman correlation, Kruskall-Wallis test) were used to examine associations between age, gender, education, and type of stroke, and the BNIS total score. Feasibility of the BNIS was investigated by comparing the time needed for assessment of the BNIS with the NPA. We hypothesized that younger patients would need less time to complete the BNIS and would obtain higher BNIS scores than older patients. Internal consistency of the BNIS total score was assessed with Cronbach's alpha for which a coefficient of at least .70 is required (Terwee et al., 2006). Floor and ceiling effects were considered present if more than $15 \%$ of patients obtained the lowest or highest possible score (Terwee et al., 2006).

Concurrent validity was assessed by examining the degree to which BNIS domain scores were related to scores on matching neuropsychological tests. Spearman correlation coefficients between .30 and .49 were considered as moderate and correlations $\geqslant .50$ strong as strong (Cohen, 1988). We expected strong correlations between the BNIS domains and matching neuropsychological tests.

The BNIS was compared to the gold standard, the brief NPA, to investigate its usefulness as a screen for cognitive impairment. For the two age groups, cross-tabulation was used to investigate sensitivity, specificity, false positives, false negatives and hit rate (true positives + true negatives) of various cutoff values. The $95 \%$ confidence intervals (CI) for sensitivity and specificity were calculated using the Wilson method (Physiotherapy evidence database, 2012). A cognitive screening instrument should have good sensitivity $(>80 \%)$ and acceptable specificity (>60\%) (Blake, McKinney, Treece, Lee, \& Lincoln, 2002). Data were analyzed using SPSS version 18.0.

\section{RESULTS}

\section{Performance on the BNIS}

All patients passed the BNIS prescreening. Scores on the BNIS and the NPA are displayed in Table 2. The median BNIS total score was 43.0 on a $0-50$ scale (interquartile range 38.0-46.3). Using the recommended BNIS cutoff values, 35 patients $(64.8 \%)$ were classified as cognitively impaired. A higher BNIS total score was significantly associated with higher education (Median 45 vs. 40; $U=133.5, p=.000)$ and lower age $(r=-.319, p=.019)$. The BNIS total score was not significantly associated with gender $(U=313.5, p=.730)$ or type of stroke $\left(\chi^{2}=.558, p=.757\right)$.

\section{Feasibility, internal consistency and floor and ceiling eects of the BNIS}

For 33 patients the time to administer the NPA and the BNIS was recorded. It took significantly less time to administer the BNIS (median $=16.0$ minutes) than the 


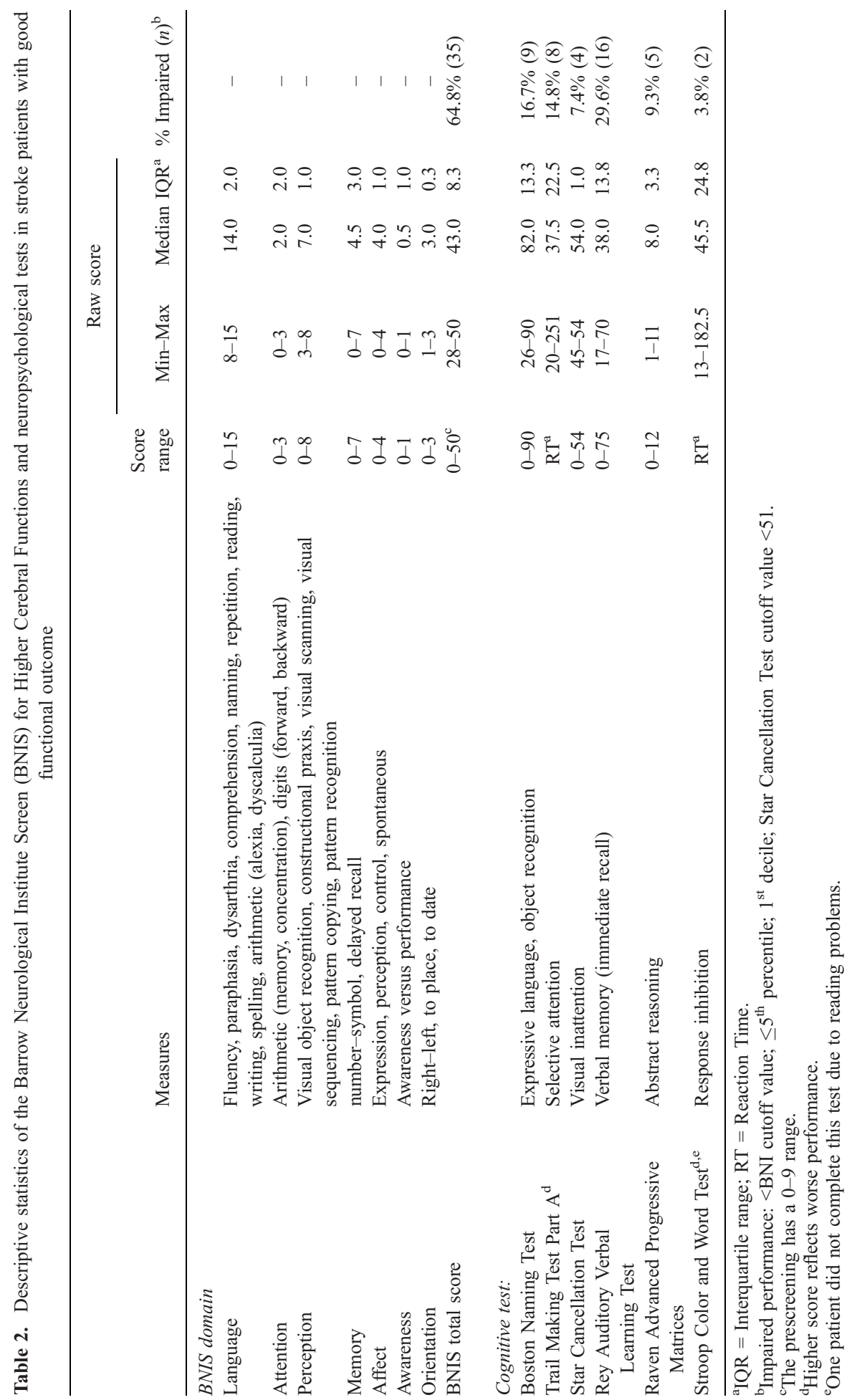


NPA (median $=32.7$ minutes; $z=-4.83, p<.01$ ). Internal consistency of the total BNIS total score was good $(\alpha=.82)$. No floor or ceiling effects were observed for the total BNIS score. None of the patients obtained the lowest possible score and 3.7\% $(n=2)$ obtained the highest possible score.

\section{Concurrent validity of the BNIS}

The BNIS total score was significantly associated with all neuropsychological tests (Table 3); strongly with the Rey Auditory Verbal Learning Test and the Raven Advanced Progressive Matrices, and moderately with the Boston Naming Test, the Trail Making Test Part A, and the Stroop Color and Word Test. Table 3 shows that the BNIS language domain was strongly associated with the Boston Naming Test short form. The BNIS attention domain was moderately associated with the Trail Making Test Part A, the Raven Advanced Progressive Matrices short form, and the Stroop Color and Word Test. The BNIS perception domain was strongly associated with the Raven Advanced Progressive Matrices short form and moderately associated with the Boston Naming Test short form, the Trail Making Test Part A, the Rey Auditory Verbal Learning Test, and the Stroop Color and Word Test. No significant associations were found between the BNIS affect domain and the seven neuropsychological tests. For the BNIS orientation domain a strong association was found with the Rey Auditory Verbal Learning Test and a moderate association with the Raven Advanced Progressive Matrices and the Trail Making Test Part A.

Table 3. Spearman correlations between the Barrow Neurological Institute Screen (BNIS) for Higher Cerebral Functions domain scores and raw neuropsychological test scores

\begin{tabular}{|c|c|c|c|c|c|c|c|}
\hline & \multicolumn{7}{|c|}{ BNIS domain $^{\mathrm{a}}$} \\
\hline & Language & Attention & Perception & Memory & Affect & Orientation & Total \\
\hline \multirow[t]{2}{*}{ Boston Naming Test } & 0.538 & 0.325 & 0.382 & 0.379 & 0.181 & 0.310 & 0.489 \\
\hline & $(0.000)^{*}$ & $(0.016)$ & $(0.004)^{*}$ & $(0.005)^{*}$ & $(0.191)$ & $(0.023)$ & $(0.000)^{*}$ \\
\hline \multirow{2}{*}{ Trail Making Test - Part $A^{b}$} & -0.227 & -0.435 & -0.381 & -0.318 & -0.307 & -0.382 & -0.498 \\
\hline & $(0.099)$ & $(0.001)^{*}$ & $(0.004)^{*}$ & $(0.019)$ & $(0.024)$ & $(0.004)^{*}$ & $(0.000)^{*}$ \\
\hline \multirow[t]{2}{*}{ Star Cancellation Test ${ }^{\mathrm{c}}$} & 0.224 & 0.271 & 0.326 & 0.260 & 0.185 & 0.262 & 0.346 \\
\hline & $(0.103)$ & $(0.047)$ & $(0.016)$ & $(0.057)$ & $(0.181)$ & $(0.056)$ & $(0.010)$ \\
\hline \multirow[t]{2}{*}{ Rey Auditory Verbal Learning Test } & 0.165 & 0.190 & 0.418 & 0.548 & 0.094 & 0.543 & 0.516 \\
\hline & $(0.233)$ & $(0.168)$ & $(0.002)^{*}$ & $(0.000)^{*}$ & $(0.501)$ & $(0.000)^{*}$ & $(0.000)^{*}$ \\
\hline \multirow[t]{2}{*}{ Raven Advanced Progressive Matrices } & 0.290 & 0.482 & 0.519 & 0.407 & 0.237 & 0.384 & 0.561 \\
\hline & $(0.033)$ & $(0.000)^{*}$ & $(0.000)^{*}$ & $(0.002)^{*}$ & $(0.084)$ & $(0.004)^{*}$ & $(0.000)^{*}$ \\
\hline \multirow[t]{2}{*}{ Stroop Color and Word Test ${ }^{\mathrm{b}, \mathrm{d}, \mathrm{e}}$} & -0.173 & -0.398 & -0.437 & -0.381 & -0.181 & -0.312 & -0.464 \\
\hline & $(0.215)$ & $(0.003)^{*}$ & $(0.001)^{*}$ & $(0.005)^{*}$ & $(0.195)$ & $(0.023)$ & $(0.000)^{*}$ \\
\hline
\end{tabular}

\footnotetext{
${ }^{a}$ No correlations were calculated for the awareness domain since this domain consists of only one item.

${ }^{\mathrm{b}}$ Higher score reflects worse performance.

${ }^{\mathrm{c}}$ The total number of cancelled stars.

${ }^{\mathrm{d}}$ One patient did not complete this test due to reading problems.

${ }^{\mathrm{e}}$ Interference score (card $\left.3-((\operatorname{card} 1+\operatorname{card} 2) / 2)\right)$.

${ }^{*} p \leq .008$.
} 


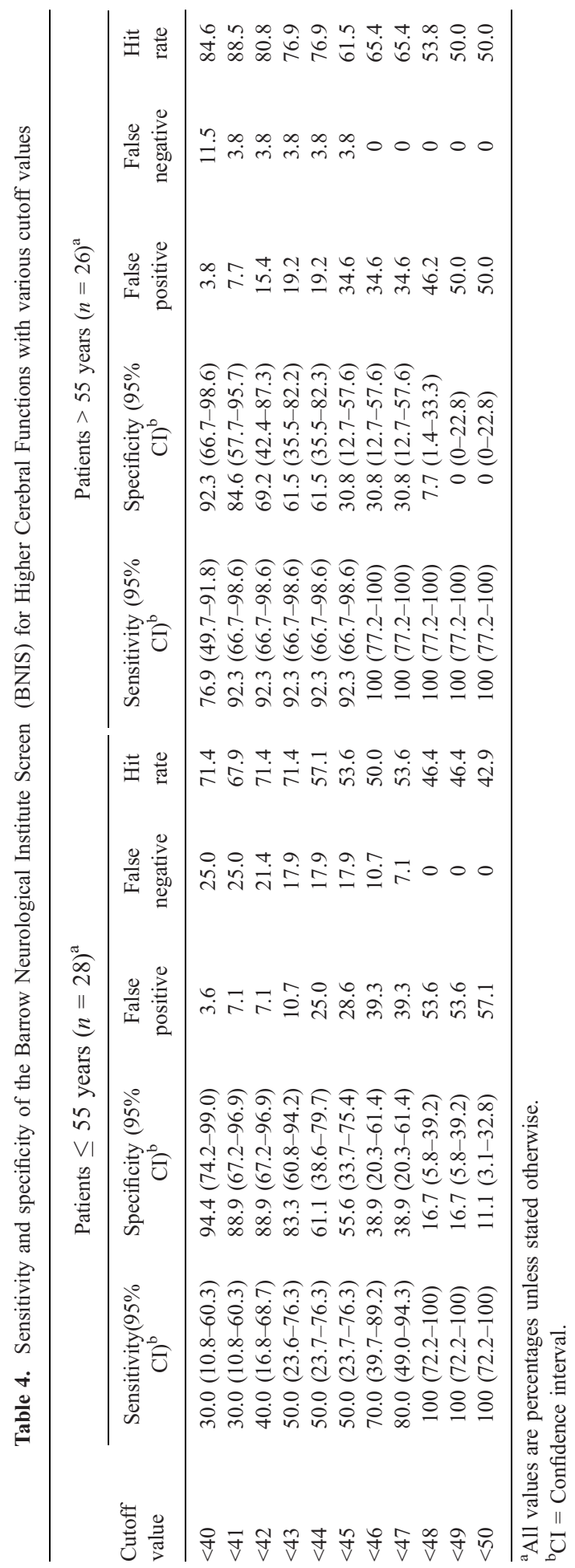




\section{Sensitivity and specificity of the BNIS}

Table 4 presents the sensitivity and specificity of the BNIS using various cutoff values for the two age groups. For patients $\leq 55$ years, the recommended cutoff value is $<47$. In our sample this yielded a good sensitivity $(80 \%)$ and a low specificity $(38.9 \%)$. There was a false negative for two patients. Both patients were impaired on the Rey Auditory Verbal Learning Test total immediate recall score and one patient was also impaired on the Stroop test. No other cutoff value showed a better sensitivity/specificity balance. For patients $>55$ years, the recommended cutoff value is $<43$. In our sample, this cutoff value yielded high sensitivity $(92.3 \%)$ whilst maintaining acceptable specificity (61.5\%). The optimum cutoff value for these patients was $<41$ which yielded high sensitivity $(92.3 \%)$ and specificity $(84.6 \%)$. There was a false negative for one patient who had impaired performance on the Boston Naming Test (short form).

\section{DISCUSSION}

This study investigated the usefulness of the BNIS for cognitive screening in stroke patients with good functional outcome. Our results showed high internal consistency, no floor or ceiling effects and adequate concurrent validity. The BNIS was less time consuming than the standard NPA and leads to one score, which is obtained immediately without the extra paper work of comparing the scores of the patient to the norms. As such, the BNIS is a feasible and valid instrument for cognitive screening in stroke patients with good functional outcome.

Stroke patients with good functional outcome are often discharged home within days after stroke without further rehabilitation services. Therefore, it is essential to minimize the risk of under diagnosing cognitive impairments. When using the recommended cutoff values, the BNIS has good to excellent sensitivity indicating that the large majority of patients with a cognitive impairment were identified. The specificity was, however, lower. For patients over 55 years of age, lowering the cutoff value to $<41$ yielded a substantial improvement in specificity while retaining excellent sensitivity. Previous studies have reported similar percentages for the sensitivity (83-96\%), specificity (46-87\%), false positives (22-48\%), and false negatives (12-20\%) of the BNIS (Prigatano, 1991; Prigatano et al., 1992; Prigatano et al., 1995; Denvall et al., 2002; Hofgren et al., 2007). A possible explanation for the lower specificity is that some of the BNIS items are relatively difficult (Truelle et al., 2004). Another possible explanation for the low specificity is that, in contrary to most neuropsychological tests, the BNIS does not yet include a correction for educational level which increases the risk of classifying low educated patients as cognitively impaired.

In total, only $6 \%$ of patients showed impairments on the NPA but were unimpaired on the BNIS. In contrast, approximately $40 \%$ of patients $\leq 55$ years of age and $19 \%$ of patients over 55 years of age, had a false positive score. It is important to note that in a screening situation, false negatives will not get further attention but false positives will. Hence, for screening purposes a low percentage of false negatives is paramount. The higher number of false positives indicates that a low score on the BNIS needs confirmation by a comprehensive NPA to diagnose cognitive impairment. 
Further studies with larger samples are needed to determine the optimum cutoff value for the two age groups.

The BNIS total score showed moderate to strong correlations with most neuropsychological tests which indicates that the BNIS is a valid measure of cognition. This is in accordance with previous studies that also reported significant associations between the BNIS and various neuropsychological measures (Prigatano, 2004; Prigatano \& Palencia, 2000; see also Lai \& Prigatano, 2004). The BNIS does not include the cognitive domains executive functioning and reasoning while stroke patients frequently experience impairments within these domains (Nys et al., 2005b; Planton et al., 2012). However, the BNIS total score was significantly associated with scores on neuropsychological tests assessing reasoning and executive functioning, which indicates that the BNIS partly covers aspects of these cognitive domains.

Some limitations of the current study should be noted. We included a small, convenience sample of relatively young stroke patients with heterogeneous diagnoses. Although small, a sample size of at least 50 patients is considered adequate in evaluating psychometric properties (Terwee et al., 2007). Our heterogeneous sample reflects daily clinical practice. Future studies with larger samples are needed to confirm our results and to assess possible differences between types of stroke.

Furthermore, the brief NPA we employed as a gold standard for establishing cognitive impairments included a core battery that was administered to all patients and additional neuropsychological tests that varied between patients. Due to this, the Trail Making Test Part B was available for only a limited number of patients and no measure of visuoconstructional ability was included.

Finally, the Dutch BNIS was not evaluated in unimpaired individuals for direct psychometric comparison with the original BNIS and we only compared the BNIS with the NPA and not with other screening instruments such as the MoCA or MMSE. Therefore, it remains unclear which screening instrument is the most useful in stroke patients with good functional outcome. Previous studies that compared the BNIS with the MMSE reported that the BNIS had better discriminative ability (Hofgren, 2009) and better accuracy regarding positive and negative predictive value (Truelle et al., 2004).To our knowledge, the BNIS has not yet been compared to the MoCA or other cognitive screening instruments. More research with larger samples is needed to compare the BNIS with other screening instruments and the original BNIS.

In conclusion, this study provides promising results for the BNIS as a measure to detect possible cognitive impairments in stroke patients with good functional outcome and to assess whether comprehensive neuropsychological testing is indicated. In addition, standard use of the BNIS may decrease the risk of under diagnosing cognitive impairments in those with good functional outcome.

\section{REFERENCES}

Aggarwal, A., \& Kean, E. (2010). Comparison of the Folstein Mini Mental State Examination (MMSE) to the Montreal Cognitive Assessment (MoCA) as a cognitive screening tool in an inpatient rehabilitation setting. Neuroscience \& Medicine, 1, 39-42. doi: 10.4236/ nm.2010.12006 
Blake, H., McKinney, M., Treece, K., Lee, E., \& Lincoln, N. B. (2002). An evaluation of screening measures for cognitive impairment after stroke. Age and Ageing, 31, 451-456. doi: 10.1093/ageing/31.6.451

Carlsson, G. E., Möller, A., \& Blomstrand, C. (2003). Consequences of mild stroke in persons $<75$ years - A 1-year follow up. Cerebrovascular Diseases, 16, 383-388. doi: 10.1159/ 000072561

Cohen, J. W. (1988). Statistical power analysis for the behavioral sciences (2nd ed.). Hillsdale, NJ: Lawrence Erlbaum Associates.

Denvall, V., Elmståhl, S., \& Prigatano, G. P. (2002). Replication and construct validation of the barrow neurological institute screen for higher cerebral function with a Swedish population. Journal of Rehabilitation Medicine, 34, 153-157. doi: 10.1080/16501970213231

Dick, J. P., Guiloff, R. J., Stewart, A., Blackstock, J., Bielawska, C., Paul, E. A., \& Marsden, C. D. (1994). Mini-mental state examination in neurological patients. Journal of Neurology, Neurosurgery, and Psychiatry, 47, 496-499. doi: 10.1136/jnnp. 47.5.496

Folstein, M. F., Folstein, S. E., \& McHugh, P. R. (1975). "Mini-Mental State". A practical method for grading the cognitive state of patients for the clinician. Journal of Psychiatric Research, 12, 189-198. doi: 10.1016/0022-3956(75)90026-6

Grace, J., Nadler, J. D., White, D. A., Guilmette, T. J., Giuliano, A. J., Monsch, A. U., \& Snow, M. G. (1995). Folstein vs modified Mini-Mental State Examination in geriatric stroke. Stability, validity, and screening utility. Archives of Neurology, 52, 477-484. doi: 10.1001/ archneur.1995.00540290067019

Hachinski, V., Iadecola, C., Petersen, R. C., Breteler, M. M., Nyenhuis, D. L., Black, S. E., \& Leblanc, G. G. (2006). National institute of neurological disorders and stroke - Canadian stroke network vascular cognitive impairment harmonization standards. Stroke, 37, 2220-2241. doi: 10.1161/01.STR.0000237236.88823.47

Hankey, G. J., \& Langhorne, P. (2006). Services for reducing the duration of hospital care for acute stroke patients. Stroke, 37, 276-277. doi: 10.1002/14651858.CD000443.pub2

Hofgren, C. (2009). Screening of cognitive functions. Evaluation of methods and their applicability in neurological rehabilitation (Doctoral thesis, University of Gothenburg, Sweden). Retrieved from http://gupea.ub.gu.se/bitstream/2077/20294/4/gupea_2077_20294_4.pdf

Hofgren, C., Esbjörnsson, E., Aniansson, H., \& Sunnerhagen, K. S. (2007). Application and validation of the barrow neurological institute for higher cerebral functions in a control population and in patient groups commonly seen in neuro-rehabilitation. Journal of Rehabilitation Medicine, 39, 547-553. doi: 10.2340/16501977-0085

Kaplan, E. F., Goodglass, H., \& Weintraub, S. (1978). The Boston Naming Test. Philadelphia, PA: Lea \& Febiger.

Koning de, I., van Kooten, F., \& Koudstaal, P. J. (1998). Value of screening instruments in the diagnosis of post-stroke dementia. Haemostasis, 28, 158-166. doi: 10.1159/000022427

Lai, F. D. M., \& Prigatano, G. P. (2004). Wechsler IQ, Hong Kong list learning test, and the BNI screen for higher cerebral functions. Barrow Quarterly, 20, 16-18.

Lezak, M. D., Howieson, D. B., \& Loring, D. W. (2004). Neuropsychological assessment (4th ed.). New York, NY: Oxford University Press.

Momtazi, R. (2004). Reliability and validity studies for the German adaptation of the BNI Screen for Higher Cerebral Functions. Barrow Quarterly 20, No. 2.

Nasreddine, Z. S., Phillips, N. A., Bedirian, V., Charbonneau, S., Whitehead, V., Collin, I., \& Chertkow, H. (2005). The Montreal Cognitive Assessment, MoCA: A brief screening tool for mild cognitive impairment. Journal of the American Geriatrics Society, 53, 695-699. doi: $10.1111 / \mathrm{j} .1532-5415.2005 .53221 . \mathrm{x}$

Nys, G. M. S., van Zandvoort, M. J. E., de Kort, P. L. M., Jansen, B. P. W., Kappelle, L. J., \& de Haan, E. H. F. (2005). Restrictions of the Mini-Mental State Examination in acute stroke. Archives of Clinical Neuropsychology, 20, 623-629. doi: 10.1016/j.acn.2005.04.001. 
Nys, G. M. S., van Zandvoort, M. J. E., de Kort, P. L. M., van der Worp, H. B., Jansen, B. P., Algra, A., \& Kappelle, L. J. (2005). The prognostic value of domain-specific cognitive abilities in acute first-ever stroke. Neurology, 64, 821-827. doi: 10.1212/01.WNL.000015 2984.28420.5A

Pendlebury, S. T., Cuthbertson, F. C., Welch, S. J. V., Mehta, Z., \& Rothwell, P. M. (2010). Underestimation of cognitive impairment by Mini-Mental State Examination versus the Montreal Cognitive Assessment in patients with transient ischemic attack and stroke. Stroke, 41, 1290-1293. doi: 10.1161/STROKEAHA.110.579888

Pendlebury, S. T., Mariz, J., Bull, L., Mehta, Z., \& Rothwell, P. M. (2012). MoCA, ACE-R, and MMSE versus the National Institute of Neurological Disorders and Stroke - Canadian stroke network vascular cognitive impairment harmonization standards neuropsychological battery after TIA and stroke. Stroke, 43, 464-469.

Physiotherapy evidence database. (2012, July 30). Confidence interval calculator. Retrieved from http://www.pedro.org.au/english/downloads/

Planton, M., Peiffer, S., Albucher, J. F., Barbeau, E. J., Tardy, J., Pastor, J., \& Pariente, J. (2012). Neuropsychological outcome after a first symptomatic ischaemic stroke with "good recovery". European Journal of Neurology, 19, 212-219. doi: 10.1111/j.1468-1331.2011. 03450.x

Prigatano, G. P. (1991). BNI Screen for Higher Cerebral Functions: Rationale and initial validation. Barrow Quarterly, 7, 2-9.

Prigatano, G. P. (2004). An analysis of the construct-related and ecological validity of the BNI screen for higher cerebral functions by Peter J. Wass: A synopsis. Barrow Quarterly, 20, 4-6.

Prigatano, G. P., Amin, K., \& Rosenstein, L. D. (1992). Validity studies on the BNI Screen for higher cerebral functions. Barrow Quarterly, 9, 2-9.

Prigatano, G. P., Amin, K., \& Rosenstein, L. D. (1995). Administration and scoring manual for the BNI Screen for higher cerebral functions. Phoenix, AZ: Barrow Neurological Institute.

Prigatano, G. P., \& Palencia, B. (2000). Halstead Impairment index, Wechsler IQ, and the BNI screen for higher cerebral functions. Barrow Quarterly, 16, 22-27.

Raven, J. (1994). Occupational user's guide: Raven's advanced progressive matrices \& mill hill vocabulary scale. Oxford, UK: Oxford Psychologists Press.

Reitan, R. (1956). Trail Making test: Manual for administration, scoring, and interpretation. Bloomington, IN: Indiana University.

Rey, A. (1958). L'examen clinique en psychologie. Paris: Presse Universitaire de France.

Schiemanck, S. K., Kwakkel, G., Post, W. M. M., Kappelle, L. J., \& Prevo, A. J. H. (2006). Predicting long-term independency in activities of daily living after middle cerebral artery stroke. Stroke, 37, 1050-1054. doi: 10.1161/01.STR.0000206462.09410.6f

Schweizer, T. A., Al-Khindi, T., \& Macdonald, R. L. (2012). Mini-Mental State Examination versus Montreal Cognitive Assessment: Rapid assessment tools for cognitive and functional outcome after aneurysmal subarachnoid hemorrhage. Journal of the Neurological Sciences, 316, 137-140. doi: 10.1016/j.jns.2012.01.003

Stroop, J. (1935). Studies of interference in serial verbal reaction. Journal of Experimental Psychology, 18, 643-662. doi: 10.1037/h0054651

Terwee, C. B., Bot, S. D. M., de Boer, M. R., van der Windt, D. A., Knol, D. L., Dekker, J., \& de Vet, H. C. (2007). Quality criteria were proposed for measurement properties of health status questionnaires. Journal of Clinical Epidemiology, 60, 34-42. doi: 10.1016/j.jclinepi.2006.03.012

Toglia, J., Fitzgerald, K. A., O’Dell, M. W., Mastrogiovanni, A. R., \& Lin, C. D. (2011). The Mini-Mental State Examination and Montreal Cognitive Assessment in persons with mild subacute stroke: Relationship to functional outcome. Archives of Physical Medicine and Rehabilitation, 5, 792-798. doi: 10.1016/j.apmr.2010.12.034 
Truelle, J. L., Marinescu, M., \& Rusina, R. (2004). A Fast Clinical Screening of Higher Cerebral Functions: From MMSE to BNIS. Barrow Quarterly, 20, 19-20.

Wade, D. T., \& Collin, C. (1988). The Barthel ADL Index: a standard measure of physical disability? International Disability Studies, 10, 64-67. doi: 10.3109/09638288809164105

Wilson, B., Cockburn, J., \& Halligan, P. W. (1987). Behavioural Inattention Test. Bury St. Edmunds, UK: Pearson Education.

Wong, G. K., Lam, S., Ngai, K., Wong, A., Mok, V., \& Poon, W. S. (2012). Evaluation of cognitive impairment by the Montreal Cognitive Assessment in patients with aneurysmal subarachnoid haemorrhage: Prevalence, risk factors and correlations with 3 month outcomes. Journal of Neurology, Neurosurgery and Psychiatry, 83, 1112-1117. doi: 10.1136/ jnnp-2012-302217 